\title{
The potential of classic and specific bioelectrical impedance vector analysis for the assessment of sarcopenia and sarcopenic obesity
}

This article was published in the following Dove Press journal:

Clinical Interventions in Aging

17 December 2012

Number of times this article has been viewed

\author{
Elisabetta Marini' \\ Roberto Buffa' \\ Bruno Saragat ${ }^{1}$ \\ Alessandra Coin ${ }^{2}$ \\ Elena Debora Toffanello² \\ Linda Berton ${ }^{2}$ \\ Enzo Manzato ${ }^{2}$ \\ Giuseppe Sergi \\ 'Department of Environmental and \\ Life Sciences, University of Cagliari, \\ Italy; ${ }^{2}$ Department of Medicine- \\ DIMED, Geriatrics Section, University \\ of Padua, Italy
}

Purpose: The aim of this paper is to investigate whether bioelectrical impedance vector analysis (BIVA) can be a suitable technique for the assessment of sarcopenia. We also investigate the potential use of specific BIVA as an indicator of sarcopenic obesity.

Subjects and methods: The sample comprised 207 free-living elderly individuals of both sexes, aged 65 to 93 years. Anthropometric and bioelectrical measurements were taken according to standard criteria. The "classic" and "specific" BIVA procedures, which respectively correct bioelectrical values for body height and body geometry, were used. Dual energy X-ray absorptiometry (DXA) was used as the reference method for identifying sarcopenic and obese sarcopenic individuals. Bioelectrical and DXA values were compared using Student's $t$-test and Hotelling's $T^{2}$ test, as well as Pearson's correlation coefficient.

Results: According to classic BIVA, sarcopenic individuals of both sexes showed higher values of resistance/height $(\mathrm{R} / \mathrm{H} ; p<0.01)$ and impedance/height $(\mathrm{Z} / \mathrm{H} ; p<0.01)$, and a lower phase angle $(p<0.01)$. Similarly, specific BIVA showed significant differences between sarcopenic and nonsarcopenic individuals (men: $T^{2}=15.7, p<0.01$; women: $T^{2}=10.7, p<0.01$ ), with the sarcopenic groups showing a lower specific reactance and phase angle. Phase angle was positively correlated with the skeletal muscle mass index (men: $\mathrm{r}=0.52, p<0.01$; women: $\mathrm{r}=0.31, p<0.01)$. Specific BIVA also recognized bioelectrical differences between sarcopenic and sarcopenic obese men $\left(T^{2}=13.4, p<0.01\right)$, mainly due to the higher values of specific $\mathrm{R}$ in sarcopenic obese individuals.

Conclusion: BIVA detected muscle-mass variations in sarcopenic individuals, and specific BIVA was able to discriminate sarcopenic individuals from sarcopenic obese individuals. These procedures are promising tools for screening for presarcopenia, sarcopenia, and sarcopenic obesity in routine practice.

Keywords: aging, body composition, BIVA, DXA

\section{Introduction}

Physiological aging is associated with large and progressive body composition variations, particularly a decline of fat-free mass (FFM), ${ }^{1}$ that expose elderly individuals to the risk of geriatric syndromes such as sarcopenia ${ }^{2}$ and sarcopenic obesity. ${ }^{3}$

According to the current consensus on definitions of the syndrome, ${ }^{4-8}$ sarcopenia is characterized by both muscle-mass reduction and low muscle strength or physical performance. ${ }^{8}$ The European Working Group on Sarcopenia in Older People (EWGSOP) also defined a "presarcopenia" stage characterized by low muscle mass in reference to the standard population, without muscle strength or functional impairment, and a "severe sarcopenia" stage that appears when the three deficits - muscle mass, strength, and function loss - are present. ${ }^{4}$
Correspondence: Elisabetta Marini Department of Environmental and Life Sciences, University of Cagliari, Cittadella Universitaria 09042 Monserrato (Cagliari), Italy

Tel +390706756607

Fax +390706756616

Email emarini@unica.it 
Sarcopenic obesity arises when a low muscle mass is associated with obesity. ${ }^{3}$ Stenholm et al ${ }^{9}$ suggested the term "obesity/ muscle impairment syndrome," which is related to the loss of muscle function rather than the loss of muscle mass only. The impact of adipose tissue on sarcopenia is also relevant because of the fat infiltration into muscle observed in older individuals, ${ }^{10}$ which can be associated with lower muscle performance. ${ }^{11,12}$ To account for these variations, the simultaneous evaluation of fat and muscle have been recommended. ${ }^{8}$

The suggested techniques for the assessment of body composition in research and practice are body-imaging techniques, computed tomography (CT), and magnetic resonance imaging (MRI) as the gold standards, and dual energy X-ray absorptiometry (DXA) as the preferred alternative method., The EWGSOP indicated bioelectrical impedance analysis (BIA) is "a good portable alternative" method. ${ }^{4}$ With its low cost and because it is quick and simple to use, BIA has also been suggested for the "systematic and repeated evaluation of FFM in clinical practice."13 However, the traditional approach using prediction equations has been questioned because of the variable level of body hydration between individuals, and the technique has been discouraged for the assessment of sarcopenia. ${ }^{6,8}$

Bioelectrical impedance vector analysis (BIVA) is an interesting alternative approach to BIA that allows the evaluation of body cell mass and hydration without the need for predictive equations. ${ }^{14}$ It has been used to evaluate many pathological conditions ${ }^{15}$ and is demonstratively sensitive to hand-grip strength variations. ${ }^{16}$ However, classic BIVA showed low efficacy when evaluating body-fat percentage. ${ }^{17} \mathrm{~A}$ recently proposed variant of classic BIVA, "specific" BIVA, has been shown to accurately identify body-fat variations in a sample of elderly Italian aged 65 to 93 years ${ }^{17}$ and in a sample of adults from the US (Buffa et al, unpublished data, 2012).

The aim of this paper is to show that BIVA can be a suitable technique for the assessment of sarcopenia in clinical routine practice by comparing the results with those obtained using DXA. Moreover, we aim to show the potential use of specific BIVA to evaluate fat mass, looking ahead to the use of this new procedure for the assessment of sarcopenic obesity.

\section{Subjects and methods Subjects}

The study group consisted of 207 individuals (132 women and 75 men) aged 65 years and over (mean age $70.8 \pm 4.0$ in women and $75.8 \pm 6.9 \mathrm{in} \mathrm{men).} \mathrm{All} \mathrm{individuals} \mathrm{were} \mathrm{born} \mathrm{and}$ resided in Italy. The volunteers were recruited from public gyms in Padua, Italy. Medical personnel from the Geriatrics
Department of Padua University established volunteers' health conditions using clinical history, clinical examination, and biochemical test results. The following were the exclusion criteria: severe cardiovascular or pulmonary disease, uncontrolled metabolic disease (diabetes, anemia, or thyroid disease), electrolyte abnormalities, cancer, or inflammatory conditions. Moreover, individuals with bioelectrical characteristics indicative of dehydration (four women and one man) on the basis of BIVA were omitted from the analyses.

In accordance with the Helsinki Declaration of 1975, as revised in 2008, all subjects were informed about the objectives and methods of the research, and the individuals consented to participate in the study.

\section{Measurements}

Detailed personal information, behavioral information, and medical history were collected by means of a structured interview. Anthropometrical (five variables), bioelectrical (two variables), and DXA (15 variables) measurements were taken in the morning by experienced operators. The anthropometric measurements (weight and height, as well as upper arm, waist, and calf circumferences) were taken in accordance with standard international criteria. ${ }^{18}$ Body mass index (BMI: weight $/$ height $^{2}\left[\mathrm{~kg} / \mathrm{m}^{2}\right]$ ) was also calculated.

The bioelectrical values of resistance $(\mathrm{R}, \mathrm{Ohm})$ and reactance (Xc, Ohm) were obtained using the impedentiometer analyzer BIA 101 (Akern, Florence, Italy), according to standard international criteria. ${ }^{19}$ The phase angle was calculated as $\arctan \mathrm{Xc} / \mathrm{R}$ (degrees) and the impedance $(\mathrm{Z}, \mathrm{Ohm})$ as $\left(\mathrm{R}^{2}+\mathrm{Xc}^{2}\right)^{0.5}$.

Classic BIVA was applied. ${ }^{14}$ Individual vectors, adjusted for height $(\mathrm{R} / \mathrm{H}, \mathrm{Ohm} / \mathrm{m}$; Xc/H, Ohm $/ \mathrm{m})$ in order to eliminate conductor length effect, can be projected on a Cartesian plane defined by $\mathrm{R} / \mathrm{H}$ and $\mathrm{Xc} / \mathrm{H}$ (R/Xc graph). Individual or sample characteristics can be compared with tolerance ellipses (50\%, $75 \%$, and $95 \%$ of cases) representing the variability of the reference population (in this case, the whole sex-specific sample under study). The major axis refers to hydration status (dehydrated individuals tending towards the upper pole), and the minor axis refers to body cell mass (higher values on the left side).

Specific BIVA ${ }^{17}$ was also applied. In order to compensate for the effect of the whole conductor volume, bioelectrical values were multiplied by a correction factor (A/L, in meters) for which area (A) and length (L) were estimated as follows:

$$
\begin{aligned}
\mathrm{A}= & (0.45 \cdot \text { arm area }+0.10 \cdot \text { waist area } \\
& +0.45 \cdot \text { calf area })\left(\mathrm{m}^{2}\right),
\end{aligned}
$$


where segment area $=\mathrm{C}^{2} / 4 \Omega$, and $\mathrm{C}(\mathrm{m})$ is the circumference of the arm, waist, and calf, respectively; $\mathrm{L}=1.1 \mathrm{H}(\mathrm{m})$. Coefficients were attributed considering the differential contribution of body segments to the whole body's resistance ${ }^{19}$ and the length proportions. ${ }^{20}$

These new bioelectrical variables, multiplied by a factor of 100 to obtain the same order of magnitude as the classic values, represent a proxy of resistivity, or specific resistance $(\mathrm{R} \mathrm{sp}, \mathrm{Ohm} \cdot \mathrm{cm})$, and reactivity, or specific reactance (Xc sp, $\mathrm{Ohm} \cdot \mathrm{cm})$. Impedivity $(\mathrm{Z} \mathrm{sp}, \mathrm{Ohm} \cdot \mathrm{cm})$ was calculated as

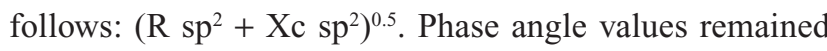
unchanged with respect to classic BIVA.

Specific resistance has a positive relation with the relative amount of fat mass, which explains the variation along the major axis of specific tolerance ellipses ${ }^{17}$ (Buffa et al, unpublished data, 2012), while specific reactance (Buffa et al, unpublished data, 2012), as well as the phase angle, ${ }^{21}$ are mainly - negatively - related to extracellular/intracellular water $(\mathrm{ECW} / \mathrm{ICW})$ ratio.

DXA fan-beam technology (QDR $4500 \mathrm{~W}$; Hologic Inc, Bedford, MA) was used to assess fat mass $\left(\mathrm{FM}_{\mathrm{DXA}}, \mathrm{kg}\right)$, fatfree mass $\left(\mathrm{FFM}_{\mathrm{DXA}}, \mathrm{kg}\right)$ (ie, the sum of lean soft tissue mass and bone mineral content), the relative amount of fatness $\left(\mathrm{FM}_{\mathrm{DXA}} \%\right)$, and the skeletal muscle mass index (SMI) (ie, the sum of lean mass of the four limbs (appendicular skeletal muscle mass [ASM]) corrected for the height squared: ASM/height $\left.{ }^{2}\left(\mathrm{~kg} / \mathrm{m}^{2}\right)\right){ }^{22}$ DXA has good reproducibility in determining soft-tissue composition and a good agreement with other reference methods. ${ }^{23}$

\section{Statistical analysis}

The cut-offs for sarcopenia were defined by the SMI values two standard deviations below the mean of a young sexspecific Rosetta Study group $\left(7.26 \mathrm{~kg} / \mathrm{m}^{2}\right.$ for men and $5.45 \mathrm{~kg} / \mathrm{m}^{2}$ for women), as suggested by Baumgartner et $\mathrm{al}^{22}$ The cut-offs for sarcopenic obesity corresponded to the sexspecific median values of the $\mathrm{FM}_{\mathrm{DXA}} \%$. Both the median $\mathrm{FM}_{\mathrm{DXA}} \%$ values of the Rosetta Study (27\% for men and 38\% for women $)^{22}$ and of our sample were applied.

Differences in the anthropometric and body composition characteristics between groups with and without sarcopenia, and between sarcopenic obese and nonobese individuals, were assessed with Student's $t$-test. Pearson's product-moment correlation coefficients between anthropometrical/bioelectrical values and body composition indicators were calculated. Given the sexrelated differences, all data analyses were stratified by sex.

The mean impedance vectors of groups with differing sarcopenia status were compared with the Hotelling's $T^{2}$ test and graphically compared with the $95 \%$ probability confidence ellipses. Mahalanobis distance $D$ was also calculated.

Statistical analyses were performed using the free software R and BIVA. All statistical tests were two-tailed, and statistical significance was assumed for a $p$-value $<0.05$.

\section{Results}

On the basis of SMI values, ${ }^{22}$ sarcopenia was diagnosed in 18 men (24.3\% of the male sample) and in five women $(3.9 \%$ of the female sample).

Sarcopenic individuals of both sexes showed lower weight $(p<0.01)$, circumference values $(p<0.01)$, BMI $(p<0.01)$, and quantities of $\mathrm{FM}_{\mathrm{DXA}}$ and $\mathrm{FFM}_{\mathrm{DXA}}(p<0.01)$, with respect to nonsarcopenic individuals (Table 1). Sarcopenic women also showed a lower percentage of $\mathrm{FM}_{\mathrm{DXA}}(p<0.05)$ and sarcopenic men a higher age $(p<0.01)$. Height was not significantly different between groups.

Classic BIVA detected significant differences between sarcopenic and nonsarcopenic groups (both sexes) due to the higher values of $\mathrm{R} / \mathrm{H}, \mathrm{Z} / \mathrm{H}$, and the lower phase angle of sarcopenic individuals (Table 1 and Figure 1), while $\mathrm{Xc} / \mathrm{H}$ values were not different between groups.

Specific BIVA also recognized significant differences between sarcopenic and nonsarcopenic individuals (men: $T^{2}=15.7, p<0.01$; women: $T^{2}=10.7, p<0.01$ ), with the sarcopenic groups showing lower specific reactance and a lower phase angle (Table 1).

Phase angle was significantly correlated with ASM (men: $\mathrm{r}=0.51, p<0.01$; women: $\mathrm{r}=0.38, p<0.05)$ and SMI (men: $\mathrm{r}=0.52, p<0.01$; women: $\mathrm{r}=0.31, p<0.01)$.

According to the $\mathrm{FM}_{\mathrm{DXA}} \%$ cut-offs of the Rosetta Study ( $27 \%$ for men and $38 \%$ for women), ${ }^{22}$ the number of sarcopenic obese individuals was very low: three men and no woman. Using the median $\mathrm{FM}_{\mathrm{DXA}}$ \% values of the present sample ( $23.8 \%$ for men and $36.4 \%$ for women), eight sarcopenic men and one sarcopenic woman had a relative amount of fat higher than the sex-specific cut-offs. Because of the numerical paucity of the female sarcopenic individuals, the subsequent analyses were performed in men only. Sarcopenic obese men showed significantly higher BMI $(p<0.01)$, waist circumference (WC) $(p<0.01)$, and SMI $(p<0.01)$, but nonobese men had similar ages and weights. Specific BIVA, but not classic BIVA, detected significant differences $\left(T^{2}=13.4, p<0.01\right)$ between groups (Table 2 and Figure 2), with specific resistance, reactance, and impedance being higher in the obese group; phase angle was not significantly different. The specific bioelectrical vectors of all sarcopenic-obese individuals were located on the right upper quadrant of the specific tolerance 
Table I Descriptive and comparative statistics: sarcopenic versus nonsarcopenic individuals

\begin{tabular}{|c|c|c|c|c|c|c|c|c|c|c|}
\hline & \multicolumn{5}{|l|}{ Men } & \multicolumn{5}{|c|}{ Women } \\
\hline & \multicolumn{2}{|c|}{$\begin{array}{l}\text { Sarcopenic } \\
(n=\mid 8)\end{array}$} & \multicolumn{3}{|c|}{$\begin{array}{l}\text { Nonsarcopenic } \\
(n=54)\end{array}$} & \multicolumn{2}{|c|}{$\begin{array}{l}\text { Sarcopenic } \\
(n=5)\end{array}$} & \multicolumn{3}{|c|}{$\begin{array}{l}\text { Nonsarcopenic } \\
(n=123)\end{array}$} \\
\hline & Mean & SD & Mean & SD & $p$ & Mean & SD & Mean & SD & $p$ \\
\hline Age & 81.5 & 7.0 & 73.8 & 5.9 & 0.000 & 70.4 & 2.6 & 70.8 & 4.1 & 0.835 \\
\hline \multicolumn{11}{|c|}{ Anthropometric and body composition variables } \\
\hline Height $(\mathrm{cm})$ & 169.2 & 7.9 & 170.3 & 6.0 & 0.552 & 155.4 & 7.5 & 156.2 & 5.6 & 0.746 \\
\hline Weight (kg) & 65.8 & 7.3 & 79.2 & 9.9 & 0.000 & 51.8 & 10.7 & 66.0 & 7.9 & 0.000 \\
\hline Upper arm crf $(\mathrm{cm})$ & 26.6 & 3.9 & 30.8 & 3.2 & 0.000 & 27.7 & 2.8 & 30.2 & 2.5 & 0.030 \\
\hline Waist crf $(\mathrm{cm})$ & 88.2 & 9.4 & 98.0 & 9.4 & 0.000 & 78.6 & 5.2 & 95.0 & 13.1 & 0.006 \\
\hline Calf crf $(\mathrm{cm})$ & 33.7 & 2.5 & 36.9 & 2.8 & 0.000 & 32.1 & 3.4 & 35.8 & 2.7 & 0.004 \\
\hline BMI $\left(\mathrm{kg} / \mathrm{m}^{2}\right)$ & 23.0 & 2.1 & 27.3 & 2.8 & 0.000 & 21.2 & 2.2 & 27.1 & 3.2 & 0.000 \\
\hline $\mathrm{FM}(\mathrm{kg})$ & 14.8 & 4.5 & 19.5 & 5.6 & 0.002 & 16.7 & 6.1 & 24.2 & 5.1 & 0.002 \\
\hline $\mathrm{FFM}(\mathrm{kg})$ & 49.5 & 4.6 & 58.0 & 5.8 & 0.000 & 34.6 & 4.3 & 40.6 & 3.9 & 0.001 \\
\hline $\mathrm{FM} \%$ & 21.9 & 5.3 & 23.9 & 4.7 & 0.135 & 30.7 & 5.4 & 36.0 & 4.4 & 0.011 \\
\hline $\mathrm{SMI}\left(\mathrm{kg} / \mathrm{m}^{2}\right)$ & 6.8 & 0.4 & 8.3 & 0.7 & 0.000 & 5.2 & 0.4 & 6.7 & 0.6 & 0.000 \\
\hline \multicolumn{11}{|c|}{ Bioelectrical variables } \\
\hline $\mathrm{R} / \mathrm{H}(\mathrm{Ohm} / \mathrm{m})$ & 331.0 & 31.5 & 272.1 & 28.4 & 0.000 & 426.4 & 53.1 & 356.5 & 31.1 & 0.000 \\
\hline $\mathrm{Xc} / \mathrm{H}(\mathrm{Ohm} / \mathrm{m})$ & 28.6 & 5.5 & 29.0 & 4.9 & 0.780 & 39.0 & 6.6 & 38.0 & 5.4 & 0.664 \\
\hline $\mathrm{Z} / \mathrm{H}(\mathrm{Ohm} / \mathrm{m})$ & 332.2 & 31.5 & 273.7 & 28.3 & 0.000 & 428.2 & 53.4 & 358.6 & 31.2 & 0.000 \\
\hline $\mathrm{R} \mathrm{sp}(\mathrm{Ohm} \bullet \mathrm{cm})$ & 387.4 & 70.8 & 393.5 & 52.6 & 0.698 & 440.5 & 65.4 & 490.2 & 64.4 & 0.094 \\
\hline $\mathrm{Xcsp}(\mathrm{Ohm} \bullet \mathrm{cm})$ & 33.7 & 8.8 & 42.4 & 10.3 & 0.002 & 40.2 & 7.3 & 52.5 & 10.6 & 0.012 \\
\hline $\mathrm{Zsp}(\mathrm{Ohm} \bullet \mathrm{cm})$ & 388.9 & 71.1 & 395.9 & 53.0 & 0.662 & 442.4 & 65.7 & 493.0 & 64.9 & 0.090 \\
\hline Phase (degrees) & 5.0 & 1.0 & 6.1 & I.I & 0.000 & 5.2 & 0.5 & 6.1 & 0.8 & 0.015 \\
\hline
\end{tabular}

Abbreviations: BMI, body mass index; crf, circumference; FFM, fat-free mass; FM, fat mass; $\mathrm{H}$, height; $\mathrm{R}$, resistance; SD, standard deviation; SMI, skeletal muscle mass index; sp, specific; Xc, reactance; Z, impedance.

ellipses, with the vectors corresponding to the three men with $\mathrm{FM}_{\mathrm{DXA}} \%$ values higher than $27 \%$ (median value of the Rosetta Study) ${ }^{22}$ outside the $95 \%$ ellipse (Figure 3).

\section{Discussion}

As shown by both classic BIVA ${ }^{14}$ and the newly proposed specific approach, ${ }^{17}$ sarcopenic individuals were characterized

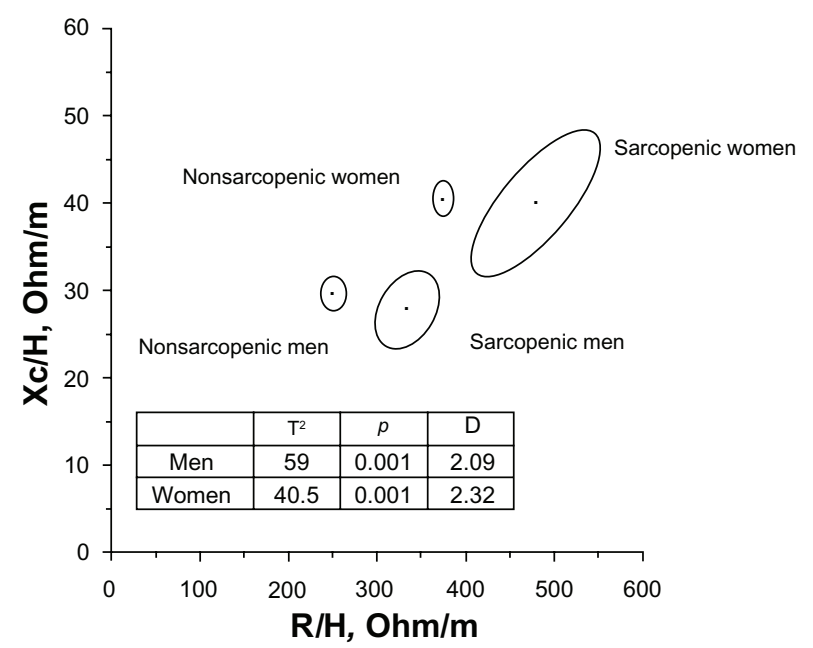

Figure I Mean impedance vectors and confidence ellipses from groups with and without sarcopenia.

Abbreviations: D, Mahalanobis distance; $H$, height; $R$, resistance; $X_{c}$, reactance. by peculiar bioelectrical characteristics. In particular, classic BIVA recognized a lower phase angle and a longer impedance vector (due to the higher values of $\mathrm{R} / \mathrm{H}$ ) in sarcopenic individuals than in nonsarcopenic individuals. These results are consistent with the theoretical expectations of BIVA, as the sarcopenic mean impedance vector was located in the region of the RXc graph corresponding to lean individuals. ${ }^{14}$ In general, a low phase angle is related to a low body cell mass ${ }^{14}$ and to a high ECW/ICW ratio. ${ }^{21}$ Castillo-Martínez et a ${ }^{24}$ found a low phase angle and a high $\mathrm{R} / \mathrm{H}$ (but also, differently from us, low $\mathrm{Xc} / \mathrm{H}$ values) in cachectic individuals. Norman et $\mathrm{al}^{16}$ obtained a similar displacement of the impedance vector in patients with low hand grip strength. The authors interpreted such vector migration as indicative of low muscle function and suggested the use of BIVA in place of hand-grip strength tests when subjects are not cooperative. ${ }^{16}$

We cannot exclude the possibility that the peculiar bioelectrical pattern found in sarcopenic individuals could be due to a loss of muscle function, as Norman et a ${ }^{16}$ suggest. However, it is certainly associated with the lower body cell mass, FFM in particular, of sarcopenic individuals.

Noticeably, the significant relation between phase angle and the reliable biomarkers of body cell mass (ASM and SMI) obtained in this research confirm the expectations of Piccoli 
Table 2 Descriptive and comparative statistics: sarcopenic versus sarcopenic obese men

\begin{tabular}{|c|c|c|c|c|c|}
\hline & \multicolumn{2}{|c|}{$\begin{array}{l}\text { Sarcopenic } \\
(\mathrm{FM} \% \leq \mathbf{2 3 . 8} \\
\mathrm{n}=10)\end{array}$} & \multicolumn{3}{|c|}{$\begin{array}{l}\text { Sarcopenic-obese } \\
\text { (FM\% > 23.8; } \\
\text { n= 8) }\end{array}$} \\
\hline & Mean & SD & Mean & SD & $p$ \\
\hline Age & 81.1 & 6.8 & 82.0 & 7.7 & 0.795 \\
\hline \multicolumn{6}{|c|}{ Anthropometric and body composition variables } \\
\hline Height $(\mathrm{cm})$ & 171.6 & 8.9 & 166.3 & 5.8 & 0.165 \\
\hline Weight $(\mathrm{kg})$ & 63.8 & 8.3 & 68.3 & 5.3 & 0.200 \\
\hline Upper arm crf (cm) & 25.3 & 2.8 & 28.3 & 4.7 & 0.110 \\
\hline Waist crf $(\mathrm{cm})$ & 83.2 & 7.6 & 94.4 & 7.9 & 0.007 \\
\hline Calf $\mathrm{crf}(\mathrm{cm})$ & 33.2 & 2.6 & 34.3 & 2.4 & 0.394 \\
\hline BMI $\left(\mathrm{kg} / \mathrm{m}^{2}\right)$ & 21.6 & 1.6 & 24.7 & 1.2 & 0.000 \\
\hline $\mathrm{FM}(\mathrm{kg})$ & 11.6 & 3.1 & 18.9 & 2.1 & 0.000 \\
\hline $\mathrm{FFM}(\mathrm{kg})$ & 50.2 & 5.4 & 48.5 & 3.4 & 0.438 \\
\hline SMI & 6.5 & 0.3 & 7.0 & 0.2 & 0.002 \\
\hline \multicolumn{6}{|c|}{ Bioelectrical variables } \\
\hline $\mathrm{R} / \mathrm{H}(\mathrm{Ohm} / \mathrm{m})$ & 327.0 & 37.3 & 335.9 & 23.7 & 0.567 \\
\hline $\mathrm{Xc} / \mathrm{H}(\mathrm{Ohm} / \mathrm{m})$ & 26.8 & 4.8 & 30.8 & 5.7 & 0.122 \\
\hline $\mathrm{Z} / \mathrm{H}(\mathrm{Ohm} / \mathrm{m})$ & 328.1 & 37.3 & 337.3 & 23.8 & 0.554 \\
\hline $\mathrm{R} \mathrm{sp}(\mathrm{Ohm} \bullet \mathrm{cm})$ & 348.7 & 49.0 & 435.9 & 65.2 & 0.005 \\
\hline $\mathrm{Xc} \mathrm{sp}(\mathrm{Ohm} \bullet \mathrm{cm})$ & 28.9 & 7.3 & 39.7 & 6.9 & 0.006 \\
\hline $\mathrm{Zsp}(\mathrm{Ohm} \bullet \mathrm{cm})$ & 349.9 & 49.2 & 437.7 & 65.2 & 0.005 \\
\hline Phase (degrees) & 4.7 & 1.0 & 5.3 & 0.9 & 0.269 \\
\hline
\end{tabular}

Abbreviations: BMI, body mass index; crf, circumference; FFM, fat-free mass; FM, fat mass; $\mathrm{H}$, height; $\mathrm{R}$, resistance; SD, standard deviation; SMI, skeletal muscle mass index; sp, specific; $X c$, reactance; Z, impedance.

et al. ${ }^{14}$ These results are also in accordance with those of Kyle et al, ${ }^{25}$ who found a similar positive relation between reactance and ASM, but disagree with those of Pietrobelli et al, ${ }^{26}$ whose results showed that phase angle does not add significantly to BIA prediction models. Moreover, the lower phase angle of sarcopenic individuals can be related to a higher ECW/ICW ratio $^{21}$ (Buffa et al, unpublished data, 2012), a parameter that can be associated in relation with $\mathrm{BCM},{ }^{27}$ which is, in turn, related to muscle mass. ${ }^{28}$ According to specific BIVA, and in particular on the basis of similar $\mathrm{R}$ sp values in sarcopenic and nonsarcopenic individuals, the mean differences in the relative quantity of fat mass were not evident (with a $p$-value slightly above the significance level in women). In effect, the $\mathrm{FM}_{\mathrm{DXA}} \%$ mean differences were not significant in men, while in women they reached a significance level of $p<0.05$ (higher $\mathrm{FM}_{\mathrm{DXA}} \%$ values in nonsarcopenic women).

Interestingly, BMI was significantly higher in the "normal" groups ( $p<0.01$ in both sexes), showing that, as recently clearly stated by Thibault and Pichard, ${ }^{13}$ it is more an indicator of body mass than body composition.

Specific BIVA, but not classic BIVA, recognized bioelectrical differences between sarcopenic and sarcopenic obese men, as shown in Figure 2. The higher values of $\mathrm{R} s p$ in sarcopenic obese individuals indicated a greater proportion of fat in their bodies (Table 2). Moreover, the impedance vectors of all sarcopenic obese individuals were located in the upper right quadrant (Figure 3), a region of the specific tolerance ellipses that was recognized as corresponding to obesity ${ }^{17}$ (Buffa et al, unpublished data, 2012). The validation of appropriate cut-offs in a larger reference sample would confirm the suitability of this procedure for the diagnosis of sarcopenic obesity.

With respect to other standard clinical methods, such as DXA or MRI, BIVA has some methodological advantages. It can easily be performed by a single operator very quickly (less than 10 minutes per patient), is completely safe because no radiation exposure is needed, and has low maintenance and operational costs.
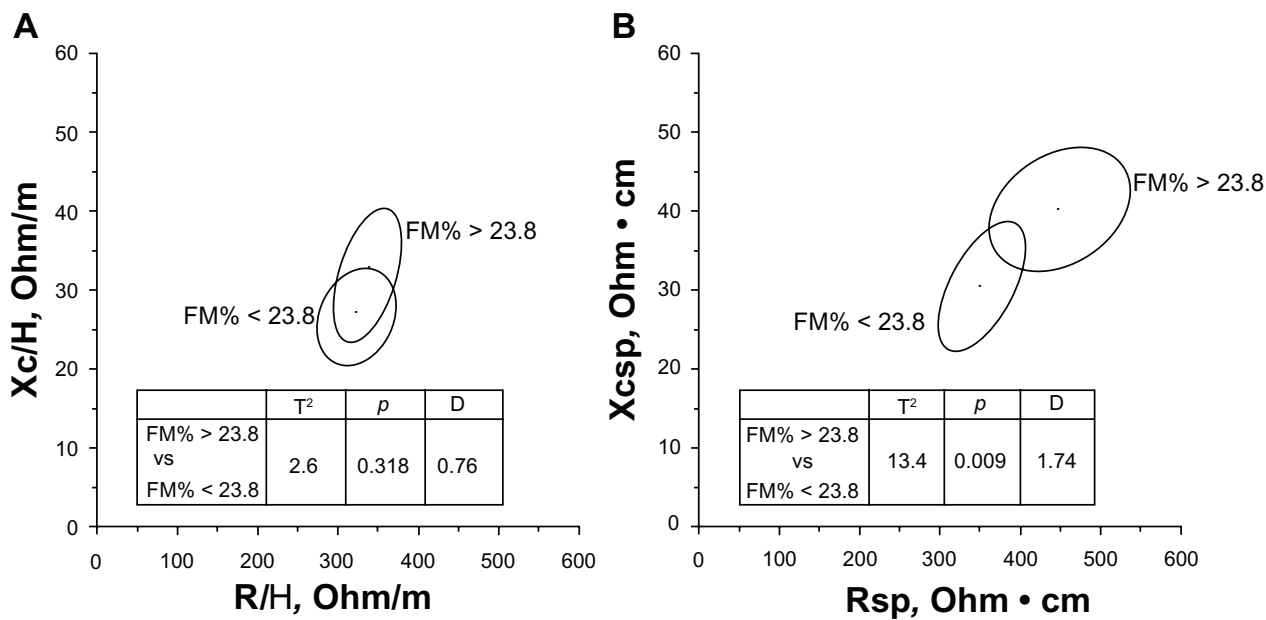

Figure 2 Mean impedance vectors and confidence ellipses from sarcopenic men with FM\% higher or lower than the median value of the sex-specific whole sample. (A) Classic BIVA; (B) specific BIVA.

Abbreviations: D, Mahalanobis distance; FM, fat mass; $H$, height; $R$, resistance; sp, specific; $X c$, reactance. 


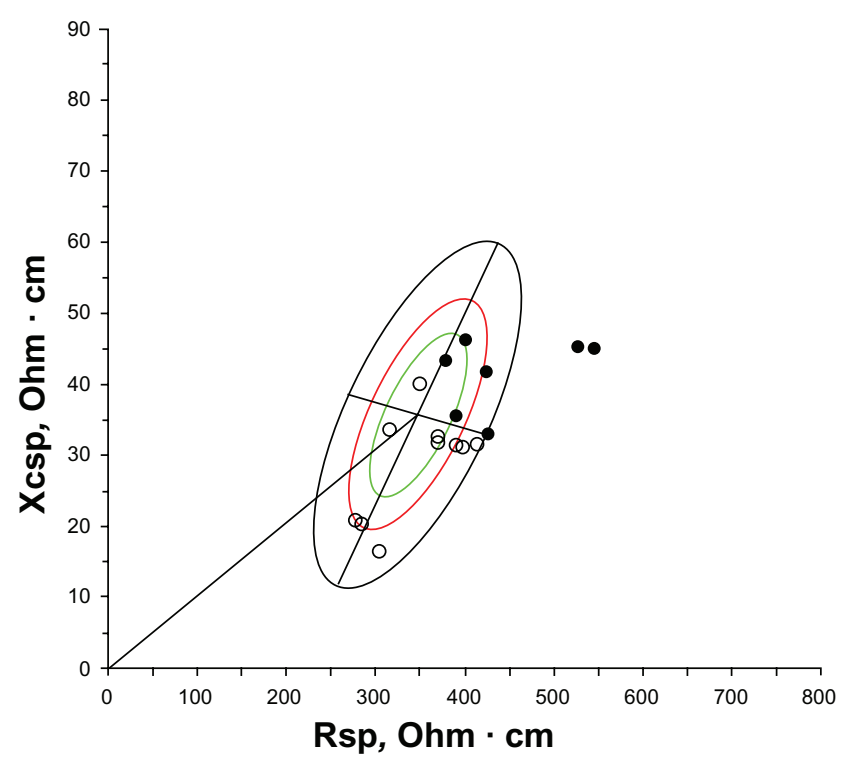

Figure 3 The individual specific vectors of sarcopenic men plotted on the sexspecific bivariate tolerance ellipse.

Notes: White dots indicate sarcopenic nonobese men; black dots indicate sarcopenic obese men.

Abbreviations: $R$, resistance; sp, specific; $X c$, reactance.

With respect to other simple adiposity indexes, such as WC and BMI, BIVA appears more adequate in recognizing body composition variations. BIVA analyzes electrical properties of tissues and is sensitive to changes of body cell mass and hydration; ${ }^{14,15}$ specific BIVA ${ }^{17}$ has been shown to accurately evaluate the relative amounts of fat and FFM, so it is probably sensitive to skeletal muscle fat infiltration and inflammatory states. According to Siervo et al, ${ }^{29} \mathrm{BMI}$ and WC showed the worst performance when classifying sarcopenic obesity in a large sample of women. Moreover, the visceral fat distribution detected by $\mathrm{WC}$ is a dimorphic character more pronounced in men than in women; in fact, even though in the present research WC showed significant differences between sarcopenic and sarcopenic obese men (Table 2), in women the correlation of WC with FM\% (r: 0.42 , $p<0.01)$ was lower than the correlation between $\mathrm{R} \mathrm{sp}$ and FM\% (r: 0.62, $p>0.01)$.

\section{Conclusion}

BIVA was confirmed to be a useful technique for detecting muscle-mass variations in sarcopenic individuals, with specific BIVA able to discriminate sarcopenic from sarcopenic obese individuals. These low-cost, simple procedures are promising tools that allow a bicompartmental evaluation of body composition, and they could be used for the screening of presarcopenia (as defined by EWGSOP, 2010), sarcopenia, and sarcopenic obesity in routine practice.

\section{Acknowledgments}

The authors thank A Piccoli and G Pastori (Department of Medical and Surgical Sciences, University of Padova, Italy) for providing the BIVA software, and Dr V Succa (Department of Environmental and Life Sciences, University of Cagliari, Italy) for her contribution in preparing the figures.

\section{Disclosure}

The authors report no conflicts of interest in this work.

\section{References}

1. Buffa R, Floris GU, Putzu PF, Marini E. Body composition variations in ageing. Coll Antropol. 2011;35(1):259-265.

2. Morley JE, Baumgartner RN, Roubenoff R, Mayer J, Nair KS. Sarcopenia. J Lab Clin Med. 2001;137:231-243.

3. Baumgartner RN. Body composition in healthy aging. Ann N Y Acad Sci. 2000;904:437-448.

4. Cruz-Jentoft AJ, Baeyens JP, Bauer JM, et al; European Working Group on Sarcopenia in Older People. Sarcopenia: European consensus on definition and diagnosis: Report of the European Working Group on Sarcopenia in Older People. Age Ageing. 2010;39:412-423.

5. Fielding RA, Vellas B, Evans WJ, et al. Sarcopenia: an undiagnosed condition in older adults. Current consensus definition: prevalence, etiology, and consequences. International working group on sarcopenia. J Am Med Dir Assoc. 2011;12:249-256.

6. Morley JE, Abbatecola AM, Argiles JM, et al; Society on Sarcopenia, Cachexia and Wasting Disorders Trialist Workshop. Sarcopenia with limited mobility: an international consensus. $J$ Am Med Dir Assoc. 2011;12:403-409.

7. Muscaritoli M, Anker SD, Argilés J, et al. Consensus definition of sarcopenia, cachexia and pre-cachexia: joint document elaborated by Special Interest Groups (SIG) "cachexia-anorexia in chronic wasting diseases" and "nutrition in geriatrics". Clin Nutr. 2010;29(2): 154-159.

8. Cesari M, Fielding RA, Pahor M, et al; International Working Group on Sarcopenia. Biomarkers of sarcopenia in clinical trialsrecommendations from the International Working Group on Sarcopenia. J Cachexia Sarcopenia Muscle. 2012;3(3):181-190.

9. Stenholm S, Harris TB, Rantanen T, Visser M, Kritchevsky SB, Ferrucci L. Sarcopenic obesity: definition, cause and consequences. Curr Opin Clin Nutr Metab Care. 2008;11:693-700.

10. Borkan GA, Hults DE, Gerzof SG, Robbins AH, Silbert CK. Age changes in body composition revealed by computed tomography. J Gerontol. 1983;38(6):673-677.

11. Visser M, Kritchevsky SB, Goodpaster BH, et al. Leg muscle mass and composition in relation to lower extremity performance in men and women aged 70 to 79 : the health, aging and body composition study. J Am Geriatr Soc. 2002;50:897-904.

12. Delmonico MJ, Harris TB, Visser M, et al; Health, Aging, and Body. Longitudinal study of muscle strength, quality, and adipose tissue infiltration. Am J Clin Nutr. 2009;90:1579-1585.

13. Thibault R, Pichard C. The evaluation of body composition: a useful tool for clinical practice. Ann Nutr Metab. 2012;60(1):6-16.

14. Piccoli A, Rossi B, Pillon L, Bucciante G. A new method for monitoring body fluid variation by bioimpedance analysis: the RXc graph. Kidney Int.1994;46:534-539.

15. Norman K, Stobäus N, Pirlich M, Bosy-Westphal A. Bioelectrical phase angle and impedance vector analysis - Clinical relevance and applicability of impedance parameters. Clin Nutr. 2012;31:854-861.

16. Norman K, Pirlich M, Sorensen J, et al. Bioimpedance vector analysis as a measure of muscle function. Clin Nutr. 2009;28(1):78-82. 
17. Marini E, Sergi G, Succa V, et al. Efficacy of specific bioelectrical impedance vector analysis (BIVA) for assessing body composition in the elderly. J Nutr Health Aging. In press 2012.

18. Lohman TG, Roche AF, Martorell R. Anthropometric Standardization Reference Manual. Champaign, IL: Human Kinetics; 1988.

19. [No authors listed]. Bioelectrical impedance analysis in body composition measurement: National Institutes of Health Technology Assessment Conference Statement. Am J Clin Nutr. 1996;64:524S-532S.

20. Marini E. Il Dimorfismo Sessuale Nella Popolazione Della Sardegna Centro-Meridionale [doctoral thesis]. Cagliari: University of Cagliari; 1992.

21. Chertow GM, Lowrie EG, Wilmore DW, et al. Nutritional assessment with bioelectrical impedance analysis in maintenance hemodialysis patients. J Am Soc Nephrol. 1995;6:75-81.

22. Baumgartner RN, Koehler KM, Gallagher D, et al. Epidemiology of sarcopenia among the elderly in New Mexico. Am J Epidemiol. 1998; 147:755-763.

23. Baumgartner RN, Stauber PM, McHugh D, Koehler KM, Garry PJ. Cross-sectional age difference in body composition in persons 60 years of age. J Gerontol A Biol Sci Med Sci. 1995;50:M307-M316.
24. Castillo-Martínez L, Colín-Ramírez E, Orea-Tejeda A, et al. Cachexia assessed by bioimpedance vector analysis as a prognostic indicator in chronic stable heart failure patients. Nutrition. 2012;28(9):886-891.

25. Kyle UG, Genton L, Hans D, Pichard C. Validation of a bioelectrical impedance analysis equation to predict appendicular skeletal muscle mass (ASMM). Clin Nutr. 2003;22(6):537-543.

26. Pietrobelli A, Morini P, Battistini N, Chiumello G, Nuñez C, Heymsfield SB. Appendicular skeletal muscle mass: prediction from multiple frequency segmental bioimpedance analysis. Eur J Clin Nutr. 1998;52(7):507-511.

27. Siervo M, Faber P, Gibney ER, et al. Use of the cellular model of body composition to describe changes in body water compartments after total fasting, very low calorie diet and low calorie diet in obese men. Int $J$ Obes (Lond). 2010;34(5):908-918.

28. Dittmar M, Reber H. New equations for estimating body cell mass from bioimpedance parallel models in healthy older Germans. Am J Physiol Endocrinol Metab. 2001;281(5):e1005-e1014.

29. Siervo M. Stephan BCM, Nasti G, Colantuoni A. Ageing, adiposity indexes and low muscle mass in a clinical sample of overweight and obese women. Obes Res Clin Pract. 2012;6:e63-e70.
Clinical Interventions in Aging

\section{Publish your work in this journal}

Clinical Interventions in Aging is an international, peer-reviewed journal focusing on evidence-based reports on the value or lack thereof of treatments intended to prevent or delay the onset of maladaptive correlates of aging in human beings. This journal is indexed on PubMed Central, MedLine, the American Chemical Society's 'Chemical Abstracts

\section{Dovepress}

Service' (CAS), Scopus and the Elsevier Bibliographic databases. The manuscript management system is completely online and includes a very quick and fair peer-review system, which is all easy to use. Visit http://www.dovepress.com/testimonials.php to read real quotes from published authors. 